\title{
Acute urinary retention in women due to urethral calculi: A rare case
}

\author{
Rafal Turo, MD; Michal Smolski, MD; Magda Kujawa, MD; Stephen C.W. Brown, MD; Richard Brough, MD; \\ Gerald N. Collins, MD
}

Department of Urology, Stepping Hill Hospital, United Kingdom

Cite as: Can Urol Assoc J 2014;8(1-2):99-100. http://dx.doi.org/10.5489/cuaj.1573

Published online February 12, 2014.

\section{Abstract:}

We present a case of a 51-year-old woman with acute urinary retention caused by a urethral calculus. Urethral calculi in women are extremely rare and are usually formed in association with underlying genitourinary pathology. In this case, however, no pathology was detected via thorough urological evaluation. We discuss the pathogenesis, clinical presentation and treatment of urethral calculi. To our knowledge, this is the second reported case of a primary urethral calculus in a female with an anatomically normal urinary tract and the first in a middle-aged Caucasian female.

\section{Introduction}

Urolithiasis is a common and recurrent disease. Prevalence and incidence rates have recently increased worldwide, especially in industrialized countries. ${ }^{1}$ Urethral stones, however, are rare and account for only $0.3 \%$ to $2 \%$ of all urinary tract stones. ${ }^{2-4}$ Most patients are men due to the urethral anatomy; few women have urethral stones. ${ }^{5-10}$ Urethral stones can be classified into primary or native (those formed in situ in the urethra) and secondary or migratory (those formed in the upper urinary tract, which descend into the urethra). Most primary urethral stones are formed in association with functional or anatomical pathology, such as chronic stasis, urinary infection, urethral diverticulum, meatal stenosis, prostate lesions, abscess cavities and fistulous tracts. Our case is remarkable because no anatomic abnormalities were detected after complete urological evaluation. To our knowledge, this is the second reported case of a primary urethral calculus in a female with an anatomically normal urinary tract and the first in a middle-aged Caucasian female. ${ }^{11}$

\section{Case report}

A 51-year-old woman, with no significant previous medical history, was admitted with acute urinary retention. A urethral catheter was not able to be passed, so we inserted a suprapubic catheter. Vaginal examination revealed a hard mass palpated in the urethra. Plain x-ray of the abdomen demonstrated a calculus between the pubic bones (Fig. 1, Fig. 2). The hard mass was not visible on inspection of the introitus. Under general anesthesia, it was visible at the urethral meatus when pressure was applied from the abdomen. A biopsy was taken to rule out dysplasia or malignancy. Furthermore, a magnetic resonance image (MRI) of the pelvis did not reveal any abnormality. Prior to the MRI, the patient felt she had passed the stone. Flexible cystoscopy was performed before we removed the suprapubic catheter. This neither revealed a stone nor any other abnormalities. After a successful trial of voiding and a normal ultrasound scanning, she was discharged with regular follow-up.

\section{Discussion}

Urethral stones are rare and most of them occur in males. Most stones pass from the kidneys or bladder and affect urethra. Primary or native urethral calculi form in abnormal environments, such as diverticula or stenosis. Previous urethral instrumentation, foreign bodies or indwelling catheters also predispose patients to stone formation.

The composition of urethral stones is mainly struvite as opposed to calcium phosphate for bladder stones. ${ }^{12,13}$ In this case, we were unable to determine stone composition; the patient passed the stone, but was unable to retrieve it.

The clinical presentation is variable and depends on the precise location of the impacted stone. In males they can mimic symptoms of prostatitis with perineal, suprapubic or rectal pain. Anterior urethral stones are generally available for palpation and often cause dysuria. In our case, the calculus was felt on deep palpation; however, its pathology 


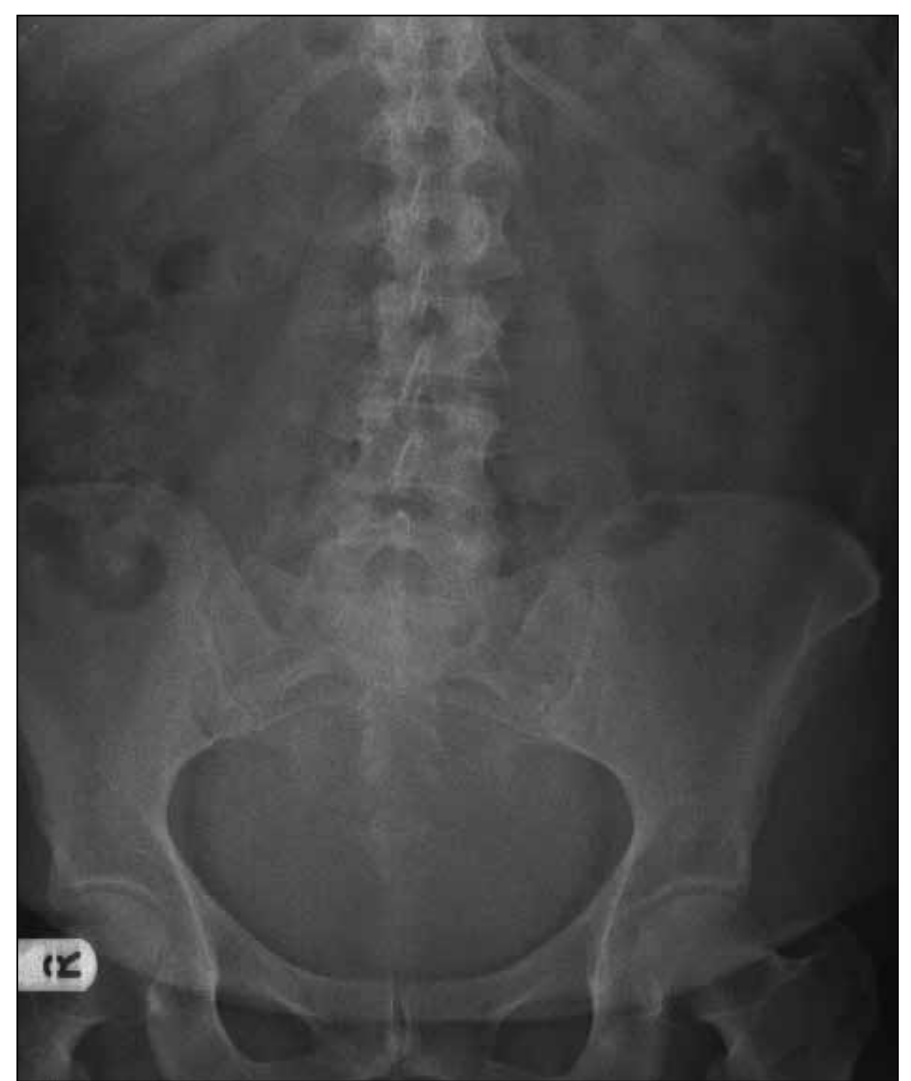

Fig. 1. X-ray kidney, ureter, bladder (KUB) scan showing calculus in the urethra.

was not obvious. Initially, the tumour was suspected and biopsies were performed. Acute urinary retention can occur irrespective of stone location.

Due to the rarity of urethral stones, its management has not been clearly defined. Smaller stones (up to $10 \mathrm{~mm}$ in diameter) could pass spontaneously. Proximal stones can be managed with cystoscopic retrograde manipulation into the bladder followed by cystolithopaxy. Large distal calculi could be managed with urethral meatotomy. Any operative approach is associated with risks of impotence, incontinence and stricture formation. In cases of large anterior urethral calculi, it is advocated to manage stones with open surgery. Urethroplasty is preferred. ${ }^{14-16}$ This approach can be complicated by urinary tract infection, fistula, urinary retention and later development of urethral stenosis. ${ }^{11,17-19}$ In any suspected case of urethral stone, the forceful manual removal of stone should be avoided. The option of manual extraction of the stone should be only considered by an experienced urologist as the abrasive surface of the calculi may damage the delicate urethral mucosa and increase the likelihood of subsequent stenosis. ${ }^{20}$

\section{Conclusion}

Urethral calculi are a rare cause of acute urinary retention in females and are more likely to pass spontaneously.

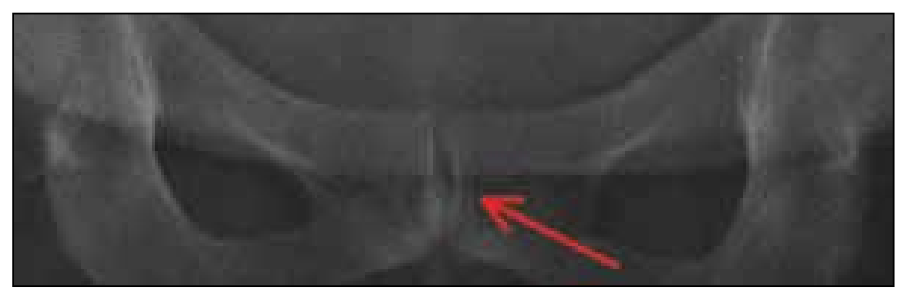

Fig. 2. Magnified part of the urethra with visible opacity measuring $1.6 \mathrm{~cm} \times 1.8$ $\mathrm{cm}$ (arrow).

Competing interests: Dr. Turo, Dr. Smolski, Dr. Kujawa, Dr. Brown and Dr. Brough all declare no competing financial or personal interests.

This paper has been peer-reviewed.

\section{References}

1. Knoll T. Epidemiology, Pathogenesis, and Pathophysiology of Urolithiasis. Eur Urol 2010 (Suppl):802-6.

2. Khai Linh VH. Chapter 84: Lower urinary tract calculi. In: Wein AJ, Kavoussi LR, Novick AC, et al, eds. Campbell's Urology. $9^{\text {th }}$ ed. St. Louis, MO: Saunders Elsevier; 2007.

3. Verit $A$, Savas $M$, Ciftciet $H$, et al. Outcomes of urethral calculi patients in an endemic region and an undiagnosed primary fossa navicularis calculus. Urol Res 2006;34:37-40. http://dx.doi.org/10.1007/ s00240-005-0008-2

4. Gogus 0, Yaman 0. An usually large anterior urethral stone. Br J Urol 1995;76:801-2.

5. Win T. Giant urethral calculus. Singapore Med J 1994;35:414-5.

6. Rivilla F, Luis A, Llanos D, et al. Giant urethral calculus in a 6-year-old girl. J Pediatr Urol 2008;4:469-71. http://dx.doi.org/10.1016/i.jpurol.2008.04.007

7. Ahmed S. Giant urethral calculus in a nine-year-old girl. Br J Urol 1985;57:108-9. http://dx.doi. org/10.1111/i.1464-410X.1985.tb08998.x

8. Chan KW, Chu WH, Law IC. Giant urethral diverticulum calculus presenting as scrotal abscess. Hong Kong Med J 2012;18:66-7.

9. Bielawska H, Epstein NL. A stone down below: A urethral stone causing acute urinary retention and renal failure. CJEM 2010;12:377-80.

10. Bello A, Maitama HY, Mbibu NH, et al. Unusual giant prostatic urethral calculus. J Surg Tech Case Rep 2010;2:30-2. http://dx.doi.org/10.4103/2006-8808.63721

11. Larkin GL, Weber JE. Giant urethral calculus: A rare cause of acute urinary retention. J Emerg Med 1996;14:707-9. http://dx.doi.org/10.1016/S0736-4679(96)00180-1

12. Bridges CH, Belville WD, Buck AS, et al. Urethral calculi. J Urol 1982;128:1036-7.

13. Shah, Abrams PH, Gaches CG, et al. Urethral calculi. Arch Ital Urol Nefrol Androl 1988;60:259-64.

14. Selli C, Barbagli G, Carini M, et al. Treatment of male urethral calculi. J Urol 1984;132:37-9.

15. Kamal BA, Anikwe RM, Darawani $H$, et al. Urethral calculi: Presentation and management. BJU Int 2004:93:549-52. http://dx.doi.org/10.1111/i.1464-410X.2003.04660.x

16. Noble JG, Chapple CR. Formation of a urethral calculus around an unusual foreign body. $\mathrm{Br} J$ Urol 1993;72:248-9.

17. Durazi MH, Samiei MR. Ultrasonic fragmentation in the treatment of male urethral calculi. $B r J$ Urol 1988;62:443-4. http://dx.doi.org/10.1111/i.1464-410X.1988.tb04393.x

18. Sharfi AR. Presentation and management of urethral calculi. Br J Urol 1991;68:271-2. http://dx.doi. org/10.1111/j.1464-410X.1991.tb15321.x

19. Walker BR, Hamilton BD. Urethral calculi managed with transurethral Holmium laser ablation. J Pediatr Surg 2001;36:E16. http://dx.doi.org/10.1053/ipsu.2001.26398

20. Okeke LI, Takure A0, Adebayo SA, et al. Urethral obstruction from dislodged bladder diverticulum stones: A case report. BMC Urol 2012;12:31. http://dx.doi.org/10.1186/1471-2490-12-31

Correspondence: Dr. Rafal Turo, Department of Urology, Stepping Hill Hospital, Stockport NHS Foundation Trust, Poplar Grove, Hazel Grove, Stockport, SK2 7JE; rturo7@yahoo.com 